Article

\title{
Soil Stabilization Using Waste Paper Fly Ash: Precautions for Its Correct Use
}

\author{
Hani Baloochi * DiD, Diego Aponte and Marilda Barra \\ Department of Civil and Environmental Engineering, Universitat Politècnica de Catalunya (UPC-BarcelonaTech), \\ Jordi Girona 1-3, 08034 Barcelona, Spain; diego.fernando.aponte@upc.edu (D.A.); marilda.barra@upc.edu (M.B.) \\ * Correspondence: hani.baloochi@upc.edu
}

Received: 17 November 2020; Accepted: 5 December 2020; Published: 7 December 2020

\begin{abstract}
This paper deals with the valorization of waste paper fly ash (WPFA) as a binder for soil stabilization. The mineralogical characterization shows the presence of free lime, as well as some non-reactive and cementitious phases. The hydration of lime is an expansive reaction and can be problematic in soil stabilization. Therefore, to study its effect on stabilized soil, an in-house experimental set-up is proposed to measure the possible expansion. Furthermore, to study the effect of water reduction and delay time on strength, unconfined compressive strength with different mixes is conducted. The obtained results showed that using WPFA causes expansion in stabilized soil, but a delay time of $30 \mathrm{~min}$, after mixing the material with water and then compacting it, can decrease the expansion. Additionally, decreasing the water content by a point of Proctor can be essential for improving the strength in soil samples, even reaching the same strength values as control samples cured at 7 days. Finally, all the results obtained in this study have shown that WPFA is a suitable material for use as a binder for soil stabilization while reducing its optimum water content, adding a proper delay time, and taking into consideration WPFA's expansive behavior at the moment of its use.
\end{abstract}

Keywords: waste paper fly ash; soil stabilization; slaking of WPFA; compressive strength development; initial and final expansion of stabilized soil

\section{Introduction}

A sector that has been criticized over the past decade is pulp and paper manufacturing [1]. This sector, other than being an intense consumer of resources, produces a large amount of waste [2]. Europe is the second largest pulp and paper producer in the world, holding $25 \%$ of world production. Producing pulp and paper generates 11 million tons of waste yearly [3,4]. It has been estimated that $25-40 \%$ of the municipal solid waste generated each year is related to paper [5].

To diminish the environmental impact of paper manufacturing, paper recycling had been growing, and some companies use only recycled paper as their raw material source. During paper manufacturing, waste sludge is produced that has been shown to be a valuable source of energy if being used in waste-to-energy plants. The resultant ash, which is called waste paper sludge ash (PSA or WSA) or waste paper ash (WPA), has been ending up in landfill sites. However, nowadays, Europe is facing the challenge of waste management, particularly industrial waste, due to some traditional disposals like landfills being restricted or banned.

In recent years, researchers have conducted many studies to find a solution for environmental problems by the utilization of waste paper ash (WPA) in the civil engineering field, like using it in mortars and concretes [6,7], supplementary cementing material [8], and bricks [9], as well as using it as a binder to stabilize clayey soils $[4,10]$ or as a potential raw material for mesoporous silica synthesis [11]. 
The WPA and other similar pulp and paper waste ashes have shown to have few cementitious properties. The composition of WPA can be variant depending on the type, grade, and quality of recycled paper [1]. The major elements present in its chemical composition normally consist of calcium, silicon, and aluminum, as well as some iron and magnesium $[4,6,7,12,13]$. The compounds present in its mineralogical composition consist of quartz, gehlenite, free lime, calcite, anorthite, and merwinite $[4,12]$. Bai and Segui $[4,12]$ found that gehlenite together with free lime are the major minerals and give the strongest diffraction pattern.

The WSA has negative and a positive effects in its use as a binder. The first negative effect is that when WSA mixes with water, it leads to expansion, due to hydration of $\mathrm{CaO}$ to form $\mathrm{Ca}(\mathrm{OH})_{2}[12]$. The second negative effect is that WSA has a high porosity that leads to a greater water/binder ratio, penalizing the compressive strength of WSA mortars [14]. Despite its negative effects, WSA has a positive effect when mixing with water, due to it providing a highly alkaline solution. The high alkaline solution leads to the release of more reactive phases like $\mathrm{Al}_{2} \mathrm{O}_{3}$ and $\mathrm{SiO}_{2}$, which belong to the WSA or from other cementitious or pozzolanic materials into the system $[13,14]$.

Some studies have shown the possibility of combining WSA with ground, granulated blast-furnace slag (GGBS) in mortars and concretes without incorporating Portland cement (PC) $[6,12,13,15]$. A concrete mix of 50:50 of WSA/GGBS gained the most strength at the age of 90 days among other ratios of WSA/GGBS blends with a water/binder ratio of 0.5 , showing a good match between WSA and GGBS [15]. It was determined that the combination of WSA and GGBS gained better strength because the amount of GGBS diluted the into the system, reducing the amount of expansive material per unit of available pore space. Likewise, by adding GGBS, the water-to-WSA ratio improves, which provides more surface for lime to be adsorbed and interact, therefore providing a better $\mathrm{pH}$ environment for a slow hydration material like GGBS [13].

Segui [4] studied WSA as the main binder for stabilizing a clayey soil. The study found that a mixture of WSA and gypsum improves the compressive strength of treated soil samples. It was found that mixing WSA and gypsum in mortars leads to a high amount of ettringite. Nevertheless, the high amount of ettringite did not surpass the maximum requirement of expansion in the soil. Additionally, despite the negative aspects of WSA, the minimum requirements for WSA to be considered as a binder are reached, particularly when mixing the WSA with gypsum. Finally, it was concluded that further studies are necessary for different types of soil.

A soil can be stabilized with either cement or lime. Additionally, to stabilize a soil according Spanish guidelines for roads and bridges (PG3) [16], a minimum of $3 \mathrm{wt} \%$ of cementitious material in the soil is necessary. In most cases, adding $3 \mathrm{wt} \%$ cement, beside the environmental problems facing consumption of raw materials, and releasing a large amount of carbon dioxide [17-22] leads to a higher strength requirement mentioned in PG3. On the other hand, as mentioned before, the use of WPA as a cementitious material that can fulfill the necessary requirement in civil engineering fields without incorporating the PC can be a great help in reducing the environmental impact of PC, and can diminish the amount of WPA that ends up in landfilled sites.

Consequently, as of today, there is not much research being conducted on entirely replacing conventional cementitious materials like cement or lime and using only recycling paper factory waste to stabilize a soil, hence the present study aims to fully substitute the traditionally used cementitious material. Furthermore, characterizations of raw materials were conducted. Proctor and compressive strength tests, along with slaking and short expansion, were carried out to determine the optimized mixture. Additionally, the long-term expansion and compressive strength was conducted to verify the possible expansion of WPFA and the strength evolution of optimized mixture. Finally, it describes the precautions associated with WPFA and the implementation of the use of WPA as a stable binder in soil, to fulfill the requirement of the Spanish guidelines (PG3) [16] that include 1.5 MPa in compressive strength for a soil type 3, called S-EST3. 


\section{Materials and Methods}

\subsection{Material}

\subsubsection{Cementitious Material (Waste Paper Fly Ash and Cement)}

The WPA was supplied by Saica, a Spanish pulp and paper recycling company. The WPA, depending on where it is collected, can be divided into two types: bottom and fly ash. Ashes that are the result of exhausted gases during combustion are commonly known as waste paper fly ash (WPFA), and this is the material used in this work. The size distribution of WPFA was made using a Beckman Coulter laser particle size analyzer (United States).

The density of WPFA was determined using standard UNE 80103 (UNE 80103, 2013). The chemical composition determination of the raw materials was conducted using the X-ray fluorescence method, with a Philips/PANalytical spectrometer, model PW2400.

This study used a powder diffraction technique to identify the crystalline phases in raw materials with a Philips X-ray Diffractometer, with a PANalytical X'Pert PRO MPD Alpha 1 diffractometer, using Cu K $\alpha$ radiation $(\lambda=1.5406 \AA, 45 \mathrm{kV}, 40 \mathrm{~mA})$. The results were interpreted with EVA using database PDF-2.

This study used a cement type IV/B(Q) $32.5 \mathrm{~N}(\mathrm{Cem} \mathrm{IV})$ as comparison. It consists of a pozzolanic cement with calcined natural pozzolana $(\mathrm{Q})$, and a resistance class of $32.5 \mathrm{~N}$.

\subsubsection{Soil}

The soil used in this study was provided by Acciona, a Spanish conglomerate group dedicated to the development and management of infrastructure. The soil is collected from an experimental section from a rural area in Zaragoza (Spain) at a depth of 0.5-1.5 m.

\subsection{Experimental Methods: Specimen Preparation and Testing}

\subsubsection{Slaking in WPFA}

As mentioned in standard EN 13282-2 [23], annex A, while working with binders containing free lime as their main composition, it is necessary to carry out the slaking procedure to avoid their possible expansion when performing different tests. As WPFA contains high amounts of free lime, a slaking test is carried out. The slaking procedure was carried out in accordance with EN 13282-2 [23], annex A. This test was conducted with different water/binder ratios. WPFA was mixed with water thoroughly and immediately placed inside the mold, and the temperature output was measured for $24 \mathrm{~h}$ using a data logger (Grant 2020 series squirrel data logger, United Kingdom). After 24 h, to verify that the reaction of $\mathrm{CaO}$ had totally occurred, to the same mixture $10 \%$ more water was added, and the temperature output was measured for another $24 \mathrm{~h}$.

\subsubsection{Modified Proctor Test}

To obtain maximum dry density and optimum water content of the soil, the study carried out the modified Proctor test for the soil-soil with 3\% cement and soil with 5\% WPFA in dry weight. The modified Proctor test was carried out according to UNE 103-501 [24]. An automatic Proctor compactor from CONTROLS (Italy) was used.

\subsubsection{Expansion in Stabilized Soil}

The procedure of swelling in soils is explained in the European standard EN 13286-49 [25]. The test measures the volumetric expansion in cylindric samples. The test is done by making samples and submerging them into a water bath. After immersing, the samples are measured using a caliper. Generally, the soils analyzed with this method are clayey and provide a good cohesive sample. Applying this method to granular soils causes desegregation of the samples, and it is not useful. 
Additionally, as mentioned in EN 13286-49 [25], the measurement by caliper makes it impossible to measure expansion correctly over time. Therefore, a homemade experiment was proposed to measure the expansion in soil samples.

The test measures the height change of a confined specimen (soil with WPFA or cement) placed vertically in a mold. The displacement is related to the reactions of cementitious material in the soil samples.

The test contained a circular plastic (PVC) mold with a diameter of $10 \mathrm{~cm}$, a height of $15 \mathrm{~cm}$, and a thickness of $0.5 \mathrm{~cm}$ to withstand the lateral forces. The mold had a perforated PVC base attached to the mold with eight screws, in order to make a uniform mold. A paper filter was added to the bottom of the mold to avoid any material loss. Then, a sample soil was ground and sieved through a $16 \mathrm{~mm}$ sieve, since the diameter of the mold was $10 \mathrm{~cm}$. The soil is mixed with WPFA and water, and then poured into the mold and compacted in 2 layers with a vibratory rammer (the goal is to reach the density obtained from the modified proctor test). The time of the compaction and water ratio depends on the density obtained from the proctor. After compacting the material, another filter was added to the top layer of the soil. Then, $125 \mathrm{~g}$ of small glass spheres with a diameter of $3 \mathrm{~mm}$ were added to the mold to have a uniform surface. To simplify the measurement, a metallic mold with a thickness of $0.5 \mathrm{~cm}$ was added. To measure the expansion in the mixture, a precise displacement measurement device with six sensors and an accuracy of $0.1 \mu \mathrm{m}$ is used. The measurement device used was an Ametek solartron model DS/50/G (United Kingdom).

Three of the six sensors were placed on the PVC mold and used as the reference point, and the other three sensors were placed inside the mold, on the metallic plate, to measure the displacement of the material. Figure 1 shows the expansion apparatus used in this study.

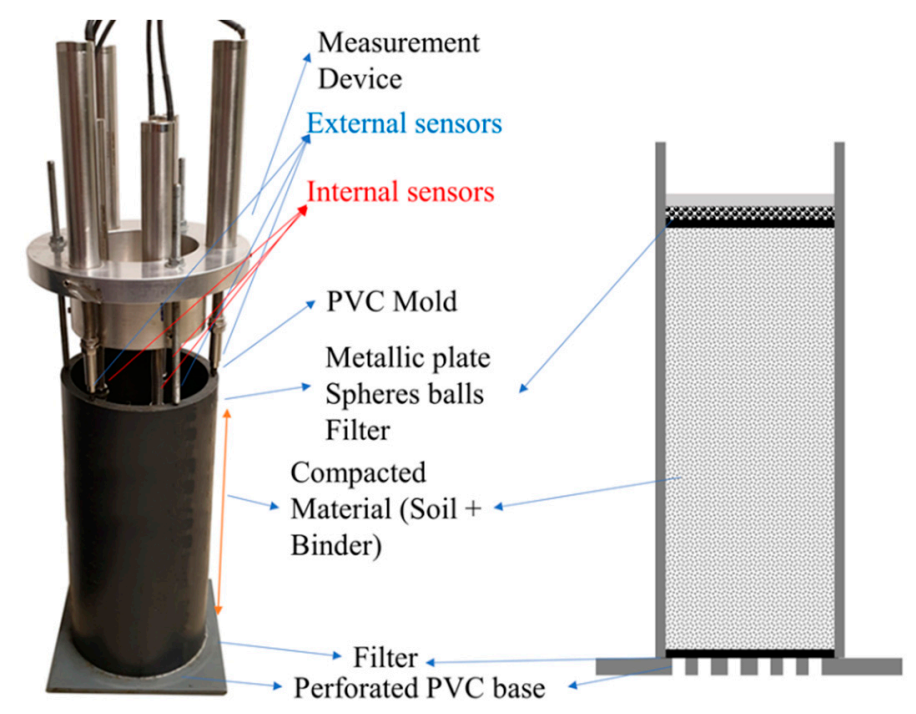

Figure 1. Expansion apparatus.

The test was carried out under seven conditions to measure the expansion in WPFA, as listed in Table 1. In order to compare the effect of water on expansion in stabilized soil, the study tested different water ratios and different delay times. Segui [4] applied a 25 min delay time when fabricating mortars, leading to a better workability; however, in this study, different delay times according to slaking results were used. It should be mentioned that the expansion test was also carried out with soil-cement samples to have a reference. In soil-cement samples, no delay time was applied. After mixing the water with the mixture, it was poured into the mold and compacted. 
Table 1. Mixture nomenclature.

\begin{tabular}{ccccc}
\hline Stages & Nomenclature & Water & Delay Time * & Comment \\
\hline 1 & T0 W10.5 & $10.5 \%$ & No delay & \\
2 & T15 W10.5 & $10.5 \%$ & 15 min & Obtained from modified proctor test \\
3 & T60 W10.5 & $10.5 \%$ & 60 min & \\
\hline 4 & T0 W8.2 & $8.2 \%$ & No delay & \\
5 & T15 W8.2 & $8.2 \%$ & 15 min & Decreasing water by $2 \%$ \\
6 & T60 W8.2 & $8.2 \%$ & 60 min & \\
\hline 7 & T180 W12 & $12 \%$ & 180 min & Increasing water by 2\% \\
\hline
\end{tabular}

* Delay time means after mixing the material (soil + waste paper fly ash (WPFA)) with water, it is left to rest (during this time, evaporation is avoided by covering the material with a plastic bag).

\subsubsection{Compressive Strength}

Spanish guidelines for roads and bridges (PG3, 2014) for a stabilized soil type 3 (S-EST3) requires a minimum of $1.5 \mathrm{MPa}$ in compressive strength at seven days, and a minimum binder content of $3 \mathrm{wt} \%$, which is considered as the amount of cement. Additionally, for stabilized soil with WPFA, the considered amount is $5 \%$ by weight of dry soil. Preliminary testing showed that using less than $5 \%$ WPFA for stabilization appeared to be insufficient to meet the requirements for PG3 (results not presented here).

To define the optimal mixture, samples were fabricated with different parameters like decreasing the water content, adding different delay times, or curing for a longer period (14 days). Six mixes were proposed to define the optimum mixture. Mix 1 was where the soil is mixed with 5\% WPFA and Proctor water content, and cured for 7 days at $20^{\circ} \mathrm{C}$ and $90 \%$ humidity. The condition in mix 2 was the same as mix 1, except that the samples were cured for 14 days instead of 7 days. In mix 3 , the experiment introduced a delay time to the mix. After mixing the soil with WPFA and water, the mixture was set to rest for an hour. Then, it was poured into the mold and compacted. The curing time was considered to be 7 days. The amount of water was considered as Proctor water content. However, in mix 4, the amount of water was decreased. Finally, in mix 5, the amount of water decreased by one point of the Proctor (same as mix 4); however, instead of a one-hour delay time, a 30 min delay was applied. A control mix with cement also was fabricated to compare the result (mix 6). The mixes are shown in Table 2.

Table 2. Mix definitions for compressive strength.

\begin{tabular}{ccccc}
\hline Mix Number & Binder Type/Content & Water Content (\%) & Curing Time (days) & Delay Time (min) \\
\hline Mix 1 & 5\%/WPFA & 10.5 & 7 & None \\
Mix 2 & 5\%/WPFA & 10.5 & 14 & None \\
Mix 3 & 5\%/WPFA & 10.5 & 7 & 60 \\
Mix 4 & 5\%/WPFA & 8.2 & 7 & 60 \\
Mix 5 & 5\%/WPFA & 8.2 & 7 & 30 \\
Mix 6 & 3\%/Cem IV & 10.0 & 7 & None \\
\hline
\end{tabular}

After defining the appropriate mix, the development of strength was studied by manufacturing more samples using mix 5 and curing them for different ages $(7,28,60,180$, and 360 days). For comparison, samples were made using cement with mix 6 and cured at the same ages as WPFA samples. For each age, four samples were made. A compressive strength test was conducted using a Toni Technik model 2020 (Germany), in accordance with EN 13286-41 [26].

\subsubsection{Long-Term Expansion Test}

Decreasing water in a mix may leave some free lime in the system, which can cause problems in the long term when the mix encounters more water (due to underground or rainwater). To study these 
scenarios, samples were fabricated and put in contact with water for 180 days, in order to determine the efficiency of delay time and water reduction.

Six samples containing soil-WPFA were prepared, as explained before in Figure 1 but in larger PVC molds ( $25 \mathrm{~cm}$ in height). The water reduction and delay time obtained from previous tests were applied, and samples were made using mix 5. The procedure is as explained in homemade sections, with the difference that the compaction was carried out in five layers (because of the height of the mold and to reach the dry density). Two of the six samples were cured in one day, and the other four were cured for seven days.

After curing, the samples were put in contact with water for 180 days under two conditions. In the first condition, the water was poured from the top of the three samples (one with one day of curing and two with seven days curing) (Figure 2a). In the second case, the remaining three samples (one with one day of curing and two with seven days of curing) were placed in water to absorb by capillary suction in a water bath, as shown in Figure 2b.

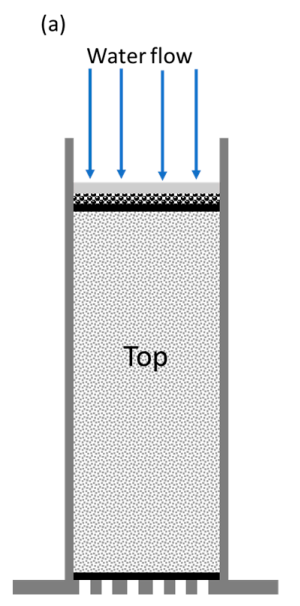

(b)

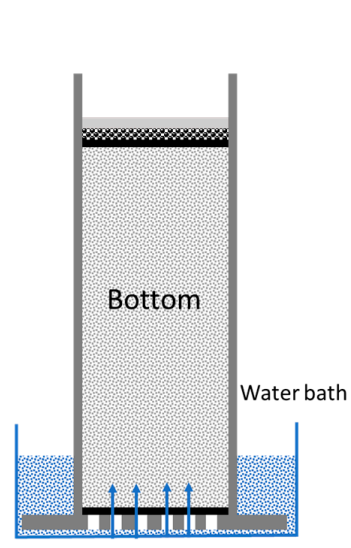

Figure 2. Long time expansion setup: (a) water flow from top, (b) water suction.

To compare the results, samples were made using cement as a binder, according to mix 6 , and were put in contact with water over the same period (180 days).

\section{Results and Discussion}

\subsection{Raw Material Properties}

Particle size distribution for WPFA is shown in Figure 3. The WPFA contains uniformly distributed fine particle sizes within the range of approximately $0.05 \mu \mathrm{m}$ to $120 \mu \mathrm{m}$.

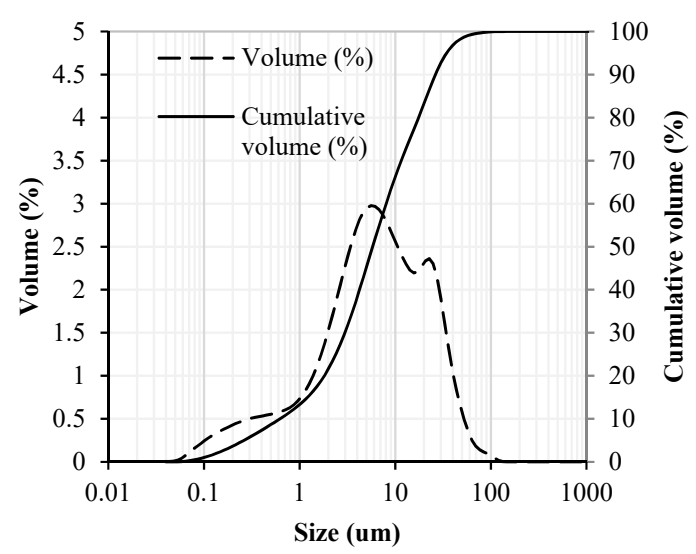

Figure 3. Particle size distribution of WPFA. 
The density of WPFA was $2.68 \mathrm{~g} / \mathrm{cm}^{3}$, which is less than the density of the cement $\left(3.05 \mathrm{~g} / \mathrm{cm}^{3}\right)$ and less than that obtained by Segui [14] $\left(2.85 \mathrm{~g} / \mathrm{cm}^{3}\right)$. Its $\mathrm{pH}$ was 12.5. The principal elements of WPFA are $\mathrm{Ca}$ and $\mathrm{Si}$, with a minor presence of $\mathrm{Al}, \mathrm{Fe}, \mathrm{Mg}$, and $\mathrm{Cl}$ (Table 3). The number of other elements were less than $2 \%$, and a loss of ignition (LOI) of $15.58 \%$ was obtained. The free lime content was determined in accordance with EN 1744-1. and 8.0\% was obtained.

Table 3. Chemical composition of the raw materials.

\begin{tabular}{ccccccccccccc}
\hline Material & $\mathrm{CaO}$ & $\mathrm{SiO}_{2}$ & $\mathrm{Al}_{2} \mathrm{O}_{3}$ & $\mathrm{Fe}_{\mathbf{2}} \mathrm{O}_{3}$ & $\mathbf{S O}_{3}$ & $\mathbf{M g O}$ & $\mathrm{MnO}$ & $\mathrm{K}_{\mathbf{2}} \mathrm{O}$ & $\mathrm{TiO}_{2}$ & $\mathrm{Cl}$ & $\sum$ Others & LOI \\
\hline Soil & 35.30 & 27.52 & 3.75 & 1.55 & 0.60 & 0.97 & 0.05 & 0.67 & 0.21 & 0.06 & 0.48 & 28.24 \\
WPFA & 48.86 & 12.58 & 12.55 & 1.01 & 0.97 & 1.82 & 0.03 & 0.36 & 1.25 & 2.33 & 2.63 & 15.58 \\
Cem IV & 35.55 & 38.11 & 10.90 & 5.59 & 2.61 & 1.51 & 0.05 & 1.66 & 0.42 & 0.06 & 0.98 & 2.5 \\
\hline
\end{tabular}

The X-ray Diffraction (XRD) results showed the presence of calcite, lime, portlandite, quartz, halite, calcium silicate, gehlenite, and aluminum in the WPFA, as shown in Figure 4. Some of the minerals are similar to WSA, like gehlenite, calcite, and lime $[4,27,28]$. In cement, the presence of calcium silicate, silica, larnite, brownmillerite, tricalcium aluminate, and gypsum have been identified, as shown in Figure 5.

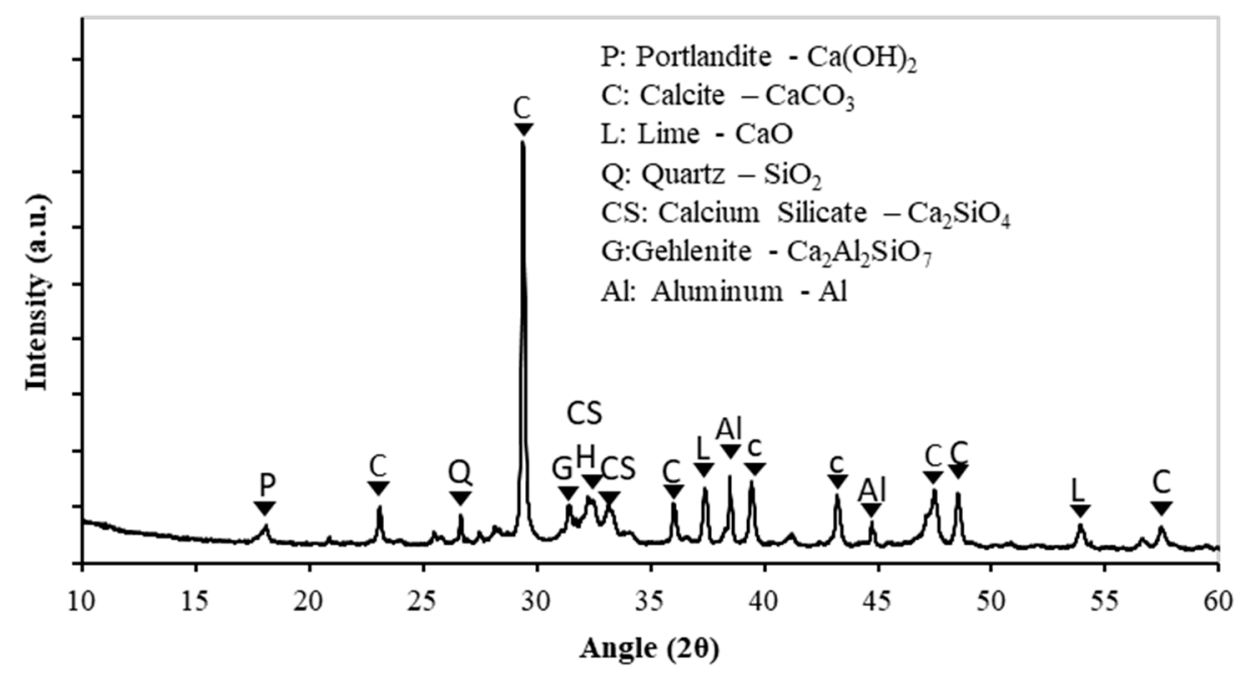

Figure 4. XRD diffractogram for WPFA.

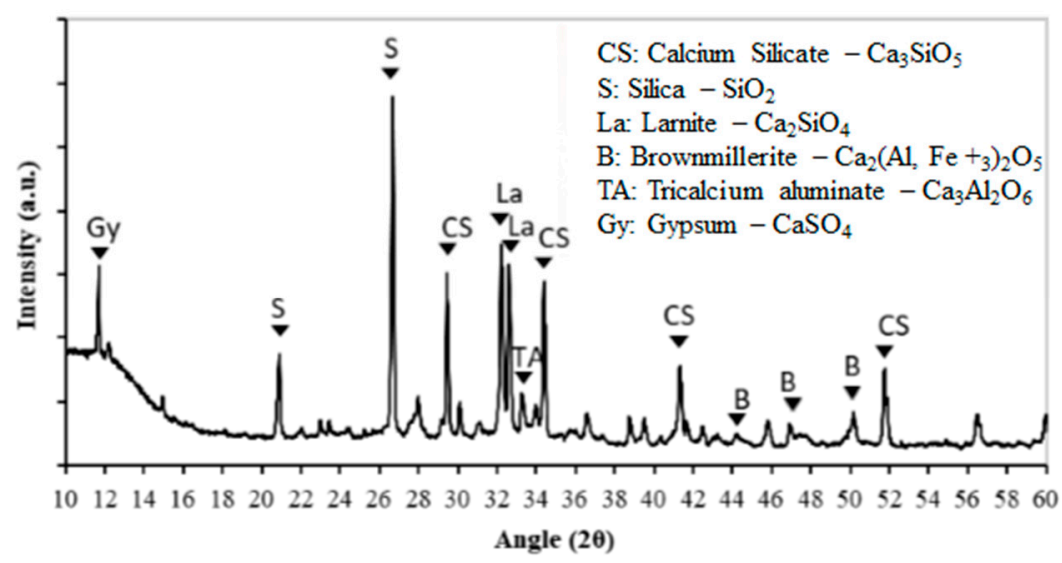

Figure 5. XRD diffractogram for cement IV.

The characterization of the soil is shown in Table 4 . 
Table 4. Soil characterization.

\begin{tabular}{lll}
\hline Test Description & Test Standard & Test Result \\
\hline Liquid limit (\%) & UNE 103103 [29] & Non-plastic \\
Plasticity index & UNE 103104 [30] & Non-plastic \\
AASHTO soil class & AASHTO M145 [31] & A-1-b \\
Unified soil classification & ASTM D2487 [32] & GM \\
Free swelling & UNE 103601 [33] & No swelling \\
Organic matter & UNE 103204 [34] & $0.87 \%$ \\
Soluble sulfate & UNE 103201 [35] & $0.27 \%$ \\
Optimum moisture (\%) & UNE 103501 [24] & $10 \%$ \\
pH & EN-12457-2 [36] & 11.8 \\
\hline
\end{tabular}

According to the ASTM and AASHTO classification systems, the soil was a GM with silt and sand, and A-1-b showing no plasticity, respectively. The particle size distribution of the soil is shown in Figure 6. The chemical composition is shown Table 3. The mineral phases found in soil are quartz, calcite, albite, biotite, chamosite, and mica.

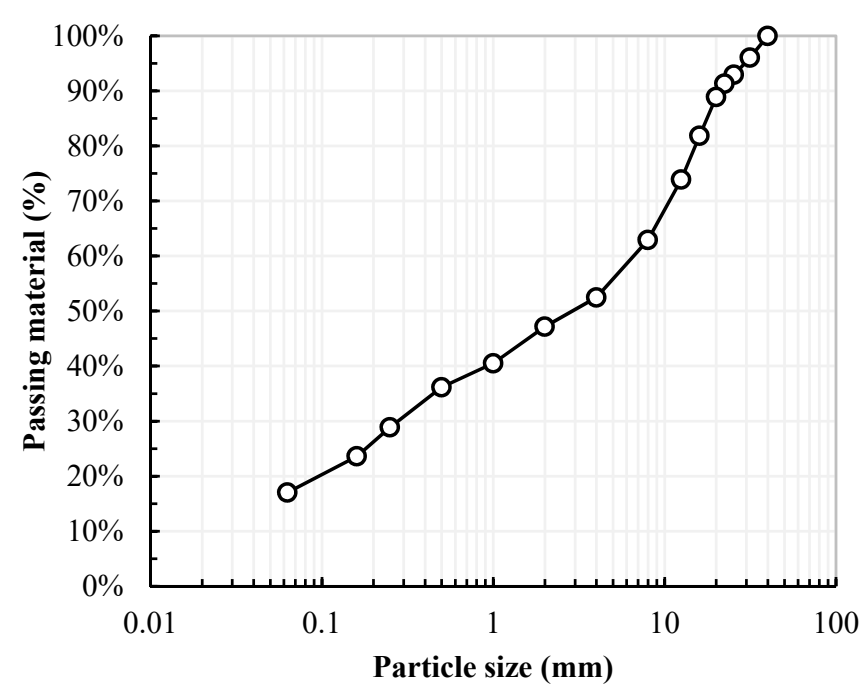

Figure 6. Size distribution of the soil.

Additionally, according to Spanish guidelines (PG3) [16], the maximum allowable amount of organic matter and soluble sulfate must be less than $1.0 \%$ and $0.7 \%$ by mass, respectively. The organic matter in soil was determined according to UNE 103-204-93 [34], and resulted in $0.87 \%$. The soluble sulfate was $0.27 \%$ [35].

\subsection{Optimum Moisture in the Mix}

The modified Proctor test showed that the Proctor curves in soil containing 3\% cement were remarkably similar to the soil shown in Figure 7. At its optimum moisture, the density in the soil containing cement was slightly higher than the soil, whereas the soil density obtained from soil containing 5\% WPFA was slightly less than that of the soil and soil-cement. Nevertheless, the amount of water increased by $0.5 \%$ in the soil with WPFA. When adding WPFA to the soil, due to its high porosity and water demand, it can lead to changes in the optimum moisture and density of the final product. 


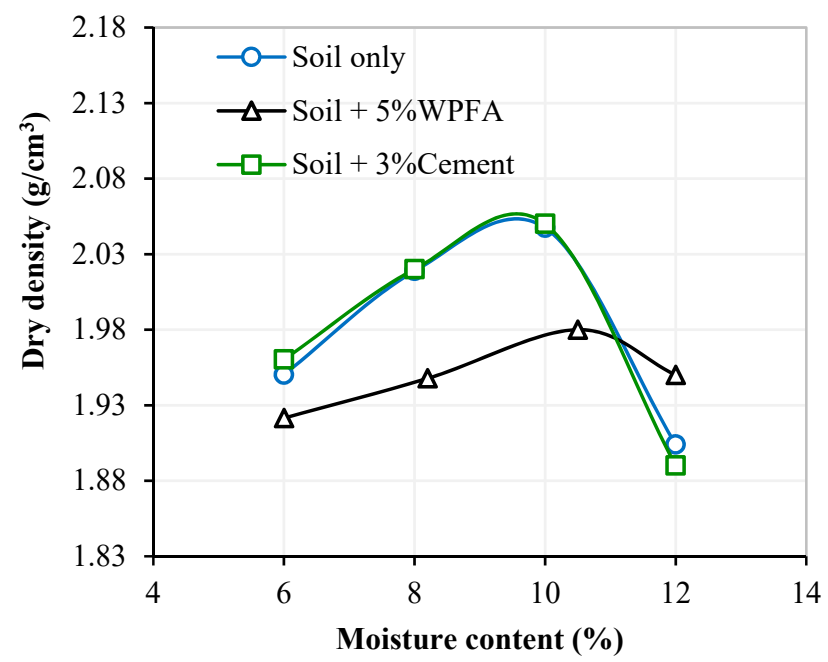

Figure 7. Modified Proctor test.

\subsection{Slaking Results}

The reaction in WPFA while mixing with water leads to a short period of the fast reaction of calcium oxide and heat output, obtaining a temperature increase, as shown in Figure 8a. This fast reaction and heat output last about six hours and tends to reach the ambient temperature. The more water that is added, the higher the heat output, up to a point $(40 \%)$ where there is more significant amount of water in the system, holding back the release of heat. With $10 \%$ water, the maximum temperature reaches at $41^{\circ} \mathrm{C}$, and with $20 \%$ around $52{ }^{\circ} \mathrm{C}$, which is the highest among the water ratios. Adding $40 \%$ water, the maximum temperatures reaches $42{ }^{\circ} \mathrm{C}, 1{ }^{\circ} \mathrm{C}$ more than $10 \%$ water. As soon as the water mixes with WPFA, the temperature rises, and after $30 \mathrm{~min}$ the temperature drops significantly; with $10 \%, 20 \%$, and $40 \%$ water, the temperature drops at $38{ }^{\circ} \mathrm{C}, 40{ }^{\circ} \mathrm{C}$, and $44{ }^{\circ} \mathrm{C}$, respectively. After an hour, the temperature tends to decrease even more, reaching the $32{ }^{\circ} \mathrm{C}, 35^{\circ} \mathrm{C}$, and $36^{\circ} \mathrm{C}$. As shown in Figure $8 \mathrm{a}$, in the first $15 \mathrm{~min}$ the reaction reaches the maximum temperature, and at $30 \mathrm{~min}$, the temperature starts to reduce. Talking into account these results, two delay times of 30 and 60 min were taken into consideration.
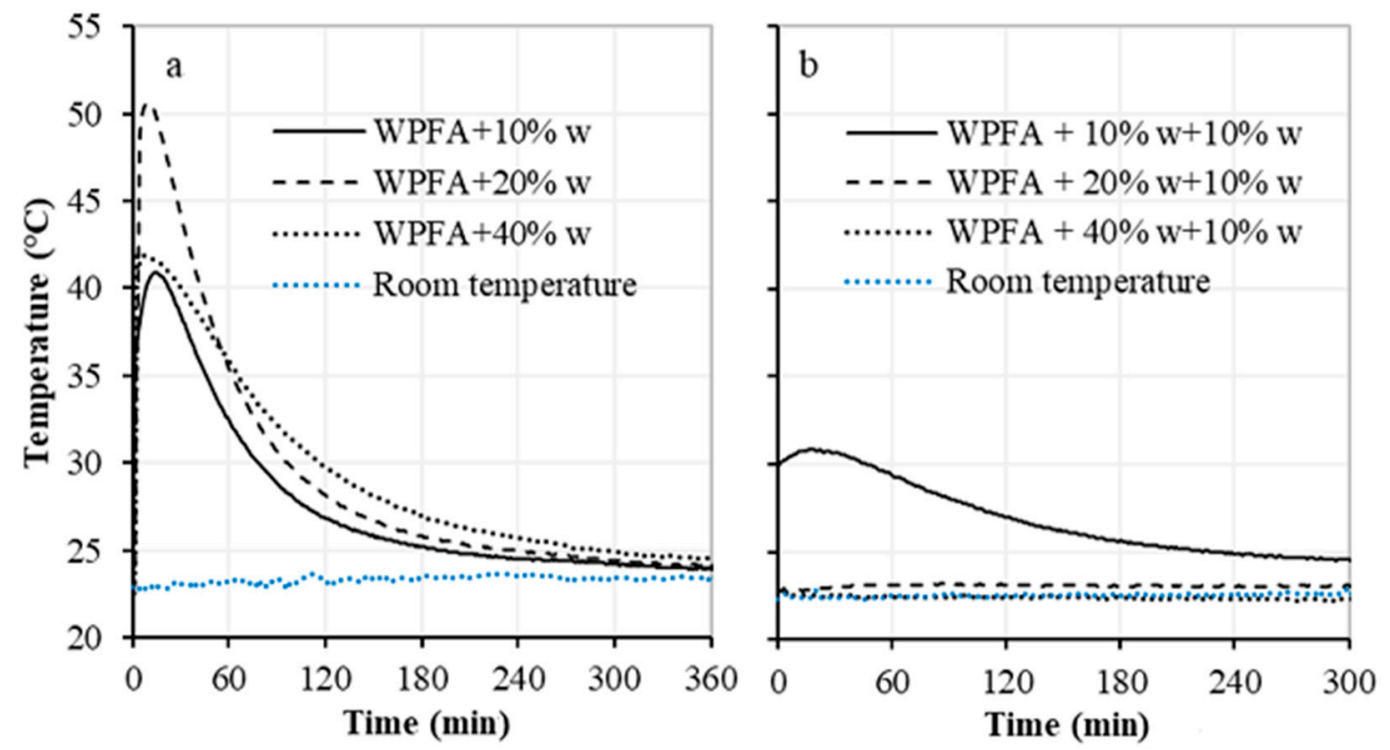

Figure 8. WPFA slaking: first stage (a), second stage (b). 
While this test was carried out with more water on the following day, by adding $10 \%$ water to the same mixtures, it was observed that the slaking in WPFA did not entirely happen in the mixture with $10 \%$ water; hence, there was a rise in temperature around $31{ }^{\circ} \mathrm{C}$ (Figure $8 \mathrm{~b}$ ). The results showed that there is a minimum water content that allows the total hydration of free lime. If the amount of water is not enough for the free lime to react and hydrate, in the long term, when it comes into contact with more water, it may lead to expansion.

\subsection{Water Reduction and Delay Time Verification}

As the WPFA is very sensitive to the amount of the water, and as free lime reaction is expansive, the homemade test was carried out with different water ratios and delay times. Figure 9a represents the expansion in the mixture with Proctor water content (10.5\%) for 0, 15, and 60 min delay times. By adding a delay time, the expansion was decreased significantly, from $0.89 \%$ to $0.64 \%$ and $0.53 \%$ $(0,15$, and 60 min delay times, respectively).
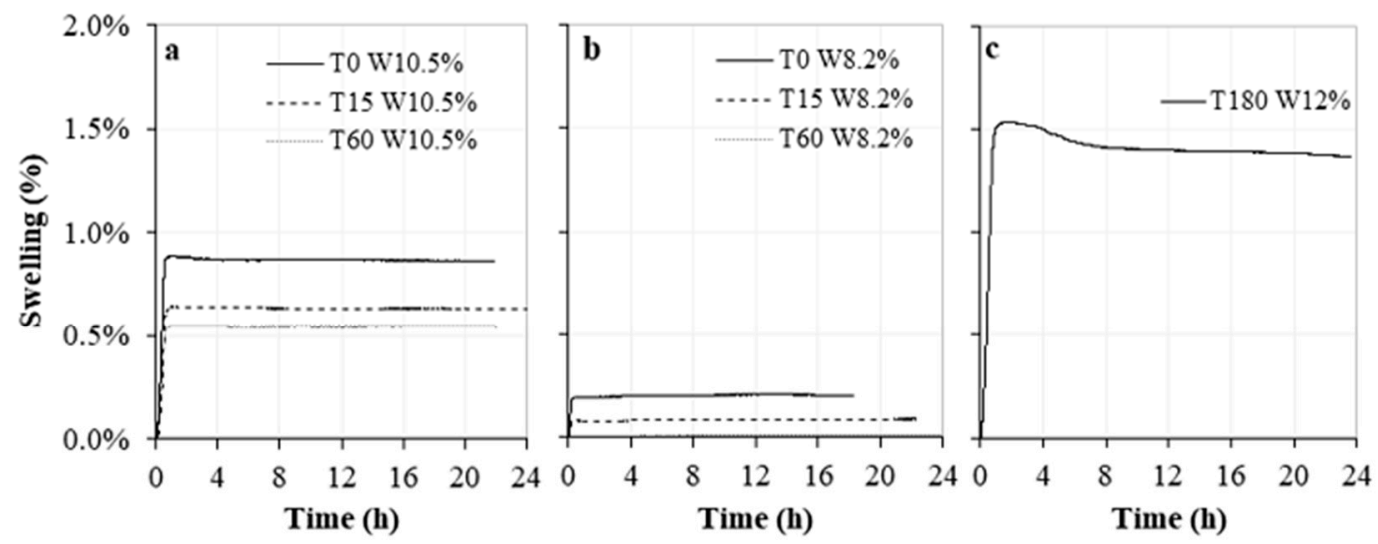

Figure 9. Expansion in soil containing 5\% WPFA: (a) Proctor water content, (b) reducing the water content by one point of Proctor, (c) increasing the water content by one point of Proctor.

Figure $9 \mathrm{~b}$ shows the result of decreasing the water ratio to $8.2 \%$. The applied delay times were equal to the previous test, and the only variation was the reduction in water by one point of Proctor. The expansion did not exceed the $0.2 \%$ in any case: with a 15 min delay, the expansion was around $0.2 \%$, and with a $60 \mathrm{~min}$ delay, the expansion was close to zero.

Variation in the quantities of water can be easily generated in a work site, and if they are higher than those of the Proctor, and since WPFA is a material sensitive to the amount of water, special care should be taken. To evaluate this, more water was added to the mix. When adding more water to the $\operatorname{mix}(12 \%)$, even with a $180 \mathrm{~min}$ delay, the expansion rose significantly to around $1.5 \%$, as shown in Figure 9c. Even when adding $3 \mathrm{~h}$ of delay time, the expansion was still considerable. The results show that WPFA was very sensitive to the amount of water and delay time. Similarly, high water content in a mix is one of the causes of poor strength development, due to an increase in porosity in the WPFA and reduction of the density of the mix.

It should be noted that the test was carried out with a soil-cement sample, and no significant expansion values were obtained (no delay time was applied for cement samples).

As shown, a delay time can reduce the expansion of the mixture by nearly half, and even adding a 15 min delay to the mixture can have a positive effect on samples. Consequently, the water reduction in the mixture leads to even greater decrease in expansion. On the other hand, by adding more water, the expansion, even with a $3 \mathrm{~h}$ delay, increases significantly.

According to the results of the slaking and expansion, it was observed that a reduction in the amount of water (from $10.5 \%$ to $8.2 \%$ ) reduced the expansion, and by adding a delay time of $60 \mathrm{~min}$, the expansion decreased significantly to nearly zero. However, in real work scenarios, waiting $60 \mathrm{~min}$ 
may be counterproductive or unusual. Therefore, it was decided to use a delay time of $30 \mathrm{~min}$ for the long-term expansion test.

Finally, to verify that the slaking occurred entirely, and see the delay time and water reduction effect over a long period on the stabilized soil, the samples were placed in continuous contact with water for 180 days, and vertical displacement was measured. The samples cured for 1 day are shown in Figure 10a, and in both cases-water absorption by suction or water poured from top-the expansion was less than $0.5 \%$. The results of samples cured for seven days by pouring the water from the top are shown in Figure 10b. The expansion in one of the samples was slightly higher than the other one. However, in both samples it was still less than $0.5 \%$. Finally, Figure 10c shows the 7 days cured sample using water suction. In both samples, the expansion was similar and less than $0.5 \%$. It should be mentioned that Segui [14] found that stabilizing a pretreatment clayey soil by adding $2 \mathrm{wt} \%$ quicklime and $6 \mathrm{wt} \%$ of a binder containing $80 \mathrm{wt} \%$ WSA and $20 \mathrm{wt} \%$ gypsum is acceptable in terms of expansion, and no significant expansion were observed.
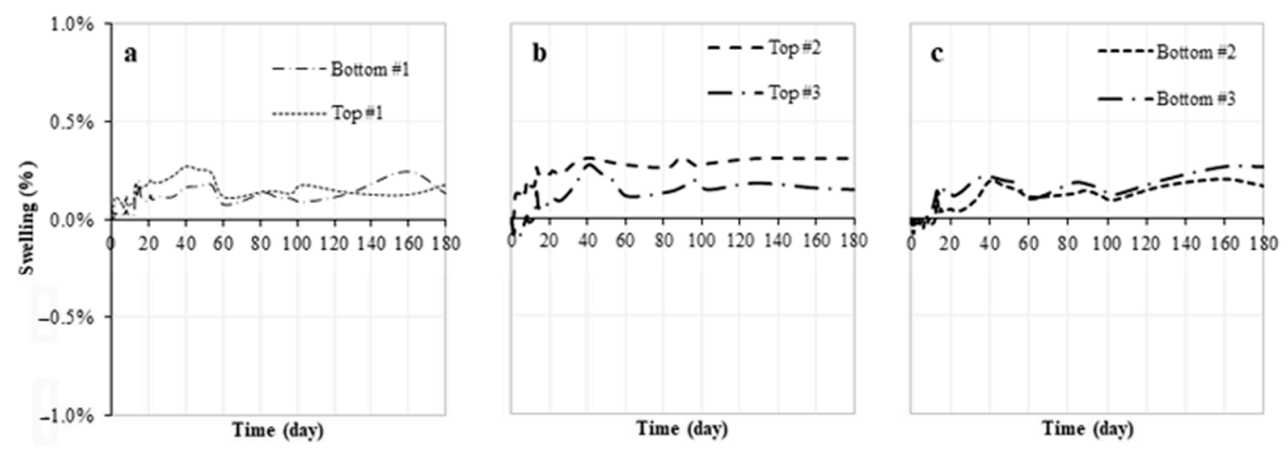

Figure 10. Expansion in stabilized soil after curing for (a) 1 day and (b,c) 7 days.

The results obtained from cement samples did not show any expansion; hence, to avoid confusion, their results are not included in Figure 10.

\subsection{Strength in Stabilized Soil}

The different variable effects, such as delay time, water reduction, and curing time on compressive strength are shown in Figure 11. Results obtained from mix 1 show that adding WPFA to the soil will improve its properties. However, it is not enough for it to fulfill PG3 requirements (1.5 MPa in compressive strength). In mix 2 , by curing the samples for 14 days, their strength improved over the second 7 days of curing by $10 \%$. Likewise, adding a one-hour delay time before compaction in mix 3 improved the properties of the soil significantly over mixes 1 and 2 (improved over $50 \%$ more than mixes 1 and 2), but it is not adequate to pass the PG3 requirement.

Likewise, by lowering the water content in the mixture and adding a one-hour delay time in mix 4, the strength improved significantly and reached around $2.16 \mathrm{MPa}$, which is adequate according to PG3. This fact was attributed to the effects of slaking and water reduction in the mix, which led to a better gain in strength. Comparing the results of mix 3 and mix 4 , by decreasing the water from $10.5 \%$ to $8.2 \%$, the results showed a growth in strength of over $1 \mathrm{MPa}$. This is believed to be due to how water reacts with WPFA, which besides producing the expansion, makes the mix more porous and causes it to have weak strength in mix 3. In mix 5, instead of an hour delay, a 30 min delay was applied. This decision was made because in practice, a one-hour delay in the job site is counterproductive. This mix showed the best improvement over the other ones by reaching 3.04 MPa in compressive strength. The experiment shows that it is crucial to add a delay time to the mix, and it can improve the strength of the soil. However, the delay time depends on factors like particle size and free lime content in WPFA. On the other hand, because the WPFA hydrates at a fast rate, a delay time of more than one hour should be avoided. 


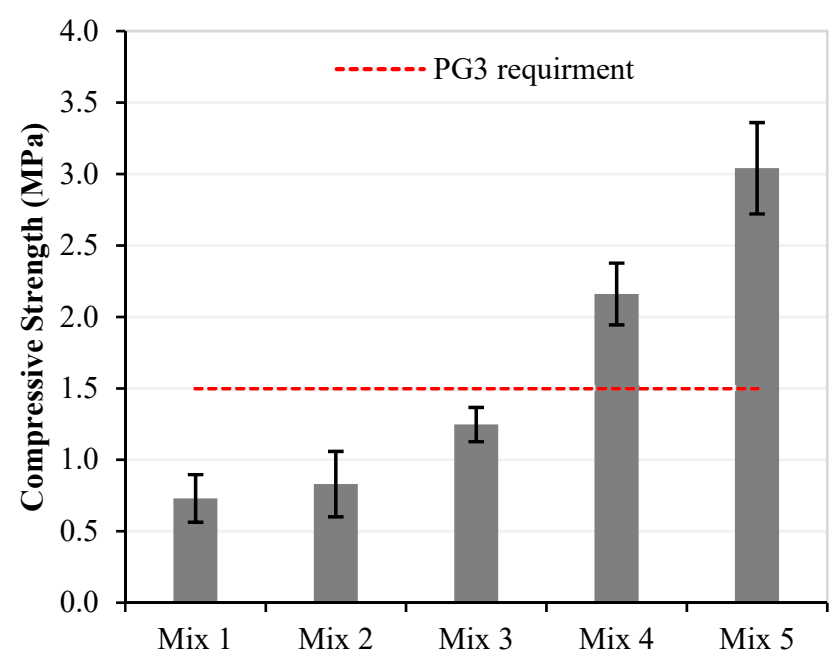

Figure 11. Compressive strength with different conditions.

It was found that applying a delay time of $30 \mathrm{~min}$ and reducing the water content by one point of Proctor gained the most strength over other properties. As mentioned by Mozaffari [13], when GGBS is added to the mix, the water-to-WSA ratio improves, showing greater strength. In this case, by reducing the water in the mix by a point of Proctor, it led to improving the water-to-WPFA ratio and gaining more strength.

However, to further study the effect of WPFA and its curing on the samples, the compressive strength test was carried out at different ages, as shown in Figure 12 with the optimum mix (mix 5). The mix gained most of its strength in the first seven days of curing, and in the later ages, from seven days to twenty-eight days, the strength improvement was only $0.18 \mathrm{MPa}$; it was more or less constant over the other periods (a small variation in compressive strength could be caused by the variability of WPFA properties).

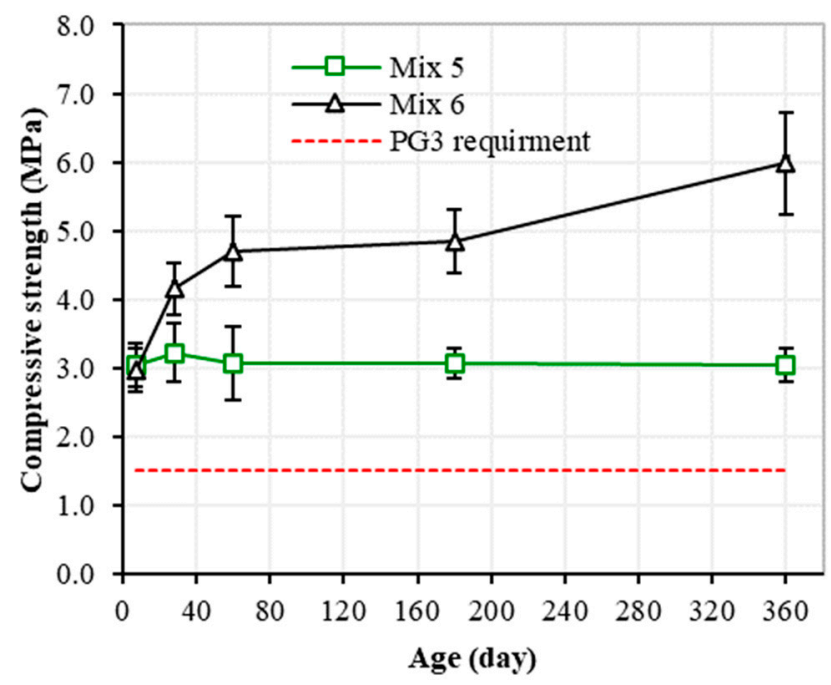

Figure 12. Compressive strength development.

However, in the case of using 3\% cement (mix 6), the strength improved over time. As the cement used in this study had pozzolanic materials, the hydration process was slower than normal cement. This type of cement tends to gain a small amount of strength on its first days of hydration, and when the pozzolanic reactions starts, an improvement in strength happens, as shown in Figure 12. Furthermore, the strength in samples with 5\% WPFA was nearly equal to cement samples only with a curing time of 
7 days, and at the rest of the ages, the cement samples improved significantly, whereas WPFA samples stayed nearly constant.

As it observed in the mineralogical phases of WPFA (see Figure 4), the presence of lime and calcium silicate, which are reactive phases when mixed with water, leads to an increase in strength. Lime present in WPFA hydrates at a fast rate and forms portlandite, giving strength at early ages. At later ages, calcium silicate hydrates due to its slow kinetic reaction, improving the strength by a tiny amount at 14 days.

\section{Conclusions}

The process of paper recycling produces a waste that can be used as fuel in waste-to-energy plants. The produced ash in this process is called waste paper ash, and it has been shown to have cementitious properties. In this study, it was verified that it is possible to replace the conventional cementitious binders (cement) with WPFA, fulfilling the mechanical requirement and durability problems relating to possible expansion.

Waste paper fly ash has some cementitious properties, and its chemical composition is mainly composed of calcium, silicon, and aluminum. The mineralogical characterization shows the existence of lime and some reactive phases (calcium silicates), which in the presence of water can react and harden.

However, WPFA has some negative characteristics that penalize its use: (i) when it comes in contact with water, due to the hydration of free lime, it leads to expansion; (ii) excessive water in the mixture penalized the use of WPFA.

The study of slaking, initial expansion and compressive strength tests showed that using WPFA in soil stabilization generates expansion and severely decreases strength. Moreover, a specific study on adding different delay times and water content led to a proposal for optimized conditions for use of WPFA, including adding a delay time and reducing the amount of water.

Moreover, the study of strength development and long-term expansion in WPFA samples showed that strength stayed constant and no significant expansion was observed. This leads to the fact that WPFA is a stable binder in the mixture.

Finally, all the results have shown that use of WPFA as a main binder is well suited for soil stabilization, although care should be taken into account. To avoid possible expansion, a delay time of $30 \mathrm{~min}$ is necessary, in conjunction with decreasing the water content in the mixture by a point of Proctor. Furthermore, due to variability in WPFA composition, experiments would be still necessary to confirm these results with other types of WPFA.

Author Contributions: Conceptualization, M.B., D.A., and H.B.; methodology, M.B., D.A., and H.B.; investigation, D.A. and H.B.; writing-original draft preparation, D.A. and H.B.; writing-review and editing, M.B., D.A., and H.B.; supervision, M.B.; project administration, M.B.; funding acquisition, M.B. All authors have read and agreed to the published version of the manuscript.

Funding: The study presented in this paper is part of the Paperchain Project. This project has received funding from the European Union's Horizon 2020 research and innovation program, under grant agreement no. 730305.

Acknowledgments: The authors would like to thank SAICA, a Spanish pulp and paper recycling company for supporting the project and Acciona, a Spanish multinational conglomerate dedicated to the development and management of infrastructure and renewable energy for their coordination.

Conflicts of Interest: The authors declare that they have no known competing financial interests or personal relationships that could have appeared to influence the work reported in this paper.

\section{References}

1. Kinuthia, J.M. Sustainability of wastepaper in construction. Sustain. Constr. Mater. 2016, 567-596. [CrossRef]

2. Talukdar, D.K. A Study of Paper Mill Lime Sludge for Stabilization of Village Road Sub-Base. Int. J. Emerg. Technol. Adv. Eng. 2015, 5, 389-393.

3. Monte, M.C.; Fuente, E.; Blanco, A.; Negro, C. Waste management from pulp and paper production in the European Union. Waste Manag. 2009, 29, 293-308. [CrossRef] 
4. Segui, P.; Aubert, J.E.; Husson, B.; Measson, M. Valorization of wastepaper sludge ash as main component of hydraulic road binder. Waste Biomass Valorization 2013, 4, 297-307. [CrossRef]

5. Nourbakhsh, A.; Ashori, A. Particleboard made from waste paper treated with maleic anhydride. Waste Manag. Res. 2010, 28, 51-55. [CrossRef]

6. Kinuthia, J.M.; O'Farrell, M.; Sabir, B.B.; Wild, S. A Preliminary Study of the Cementitious Properties of Wastepaper Sludge Ash Ground Granulated Blast-Furnace Slag (Wsa-Ggbs) Blends. In Recovery and Recycling of Paper; Thomas Telford Publishing: London, UK, 2001; pp. 93-104, ISBN 0-7277-4896-3.

7. O'Farrell, M.; Chaipanich, A.; Kinuthia, J.M.; Sabir, B.B.; Wild, S. A New Concrete Incorporating Wastepaper Sludge Ash (WSA). Innov. Dev. Concr. Mater. Constr. 2002, 149-158. [CrossRef]

8. Frías, M.; García, R.; Vigil, R.; Ferreiro, S. Calcination of art paper sludge waste for the use as a supplementary cementing material. Appl. Clay Sci. 2008, 42, 189-193. [CrossRef]

9. Liaw, C.T.; Chang, H.L.; Hsu, W.C.; Huang, C.R. A novel method to reuse paper sludge and co-generation ashes from paper mill. J. Hazard. Mater. 1998, 58, 93-102. [CrossRef]

10. Khalid, N.; Mukri, M.; Kamarudin, F.; Arshad, M.F. Clay soil stabilized using waste paper sludge ash (WPSA) mixtures. Electron. J. Geotech. Eng. 2012, 17, 1215-1225.

11. Miricioiu, M.G.; Niculescu, V.C. Fly ash, from recycling to potential raw material for mesoporous silica synthesis. Nanomaterials 2020, 10, 474. [CrossRef]

12. Bai, J.; Chaipanich, A.; Kinuthia, J.M.; O’Farrell, M.; Sabir, B.B.; Wild, S.; Lewis, M.H. Compressive strength and hydration of wastepaper sludge ash-ground granulated blastfurnace slag blended pastes. Cem. Concr. Res. 2003, 33, 1189-1202. [CrossRef]

13. Mozaffari, E.; Kinuthia, J.M.; Bai, J.; Wild, S. An investigation into the strength development of Wastepaper Sludge Ash blended with Ground Granulated Blastfurnace Slag. Cem. Concr. Res. 2009, 39, 942-949. [CrossRef]

14. Segui, P.; Aubert, J.E.; Husson, B.; Measson, M. Characterization of wastepaper sludge ash for its valorization as a component of hydraulic binders. Appl. Clay Sci. 2012, 57, 79-85. [CrossRef]

15. Kinuthia, J.M.; Gailius, A. Compressive Strength and Workability of Concrete Utilising Waste-Paper Sludge Ash and Ground Granulated Blast Furnace Slag as Binder. Modern Building Materials Structures Techniques. In Proceedings of the 7th Internatinal Conference, Vilnius, Lithuania, 16-18 May 2001.

16. PG-3 General technical specifications for road and bridge works. Art. 542. Bitum. Mix. Like Bitum. Concr. 2014, 514, 514.

17. Behnood, A. Soil and clay stabilization with calcium- and non-calcium-based additives: A state-of-the-art review of challenges, approaches and techniques. Transp. Geotech. 2018, 17, 14-32. [CrossRef]

18. Amit, S.K.S.; Islam, M.R. Application of Paper Sludge Ash in Construction Industry-A review. In Proceedings of the 3rd International Conference on Civil Engineering for Sustainable Development (ICCESD 2016), Khulna, Bangladesh, 12-14 February 2016; pp. 737-746.

19. Liu, J.; Zhang, S.; Wagner, F. Exploring the driving forces of energy consumption and environmental pollution in China's cement industry at the provincial level. J. Clean. Prod. 2018, 184, 274-285. [CrossRef]

20. Umar, U.A.; Khamidi, M.F.; Tukur, H. Sustainable building material for green building construction, conservation and refurbishing. In Proceedings of the Management in Construction Research Association (MiCRA) Postgraduate Conference, Kuala Lumpur, Malaysia, 5-6 December 2012; pp. 2-7.

21. Wang, Y.; Zhu, Q.; Geng, Y. Trajectory and driving factors for GHG emissions in the Chinese cement industry. J. Clean. Prod. 2013, 53, 252-260. [CrossRef]

22. Zhang, N.; Wu, L.; Liu, X.; Zhang, Y. Structural characteristics and cementitious behavior of basic oxygen furnace slag mud and electric arc furnace slag. Constr. Build. Mater. 2019, 219, 11-18. [CrossRef]

23. UNE-EN 13282-2: 2016. AENOR Hydraulic road binders-Part 2: Normal Hardening Hydraulic Road Binders-Composition, Specifications and Conformity Criteria. Available online: https://www.aenor.es (accessed on 20 October 2020).

24. UNE-103501 Geotechnic. Compactation Test. Modified Proctor 1994, 6. Available online: https://www.aenor. $\mathrm{com} /$ (accessed on 20 October 2020).

25. Asociación Española de Normalización y Certificación Unbound and Hydraulically Bound MixturesPart 49: Accelerated Swelling Test for Soil Treated by Lime and/or Hydraulic Binder 2008. Available online: https://www.aenor.es (accessed on 20 October 2020). 
26. UNE-EN-13286-41: 2003 Unbound and Hydraulically Bound Mixtures. Test Method for Determination of the Compressive Strength of Hydraulically Bound Mixtures. Available online: https://www.aenor.es (accessed on 20 October 2020).

27. Spathi, C.; Young, N.; Heng, J.Y.Y.; Vandeperre, L.J.M.; Cheeseman, C.R. A simple method for preparing super-hydrophobic powder from paper sludge ash. Mater. Lett. 2015, 142, 80-83. [CrossRef]

28. Wong, H.S.; Barakat, R.; Alhilali, A.; Saleh, M.; Cheeseman, C.R. Hydrophobic concrete using waste paper sludge ash. Cem. Concr. Res. 2015, 70, 9-20. [CrossRef]

29. AENOR Determination of the Liquid Limit of a Soil by the Casagrande Apparatus Method; UNE 103103:1994. 1994. Available online: https://www.aenor.es (accessed on 20 October 2020).

30. Asociación Española de Normalización y Certificación. UNE 103104 Test for Plastic Limit of a Soil. 1996. Available online: https://www.aenor.es (accessed on 20 October 2020).

31. AASHTO Standard Specification for Classification of Soils and Soil-Aggregate Mixtures for Highway Construction Purposes. Am. Assoc. State Highw. Transp. Off. (AASHTO) 1991, 91, 1-7.

32. ASTM D2487 Standard Practice for Classification of Soils for Engineering Purposes (Unified Soil Classification System). Am. Soc. Test. Mater. 2011. [CrossRef]

33. Asociación Española de Normalización y Certificación. UNE 103601 Test for Free Swelling of Soils in Oedometer Device. 1996. Available online: https://www.aenor.es (accessed on 20 October 2020).

34. UNE 103204 UNE 103204, Organic Matter Content of a Soil by the Potassium Permanganate Method. 1993. Available online: https://www.aenor.es (accessed on 20 October 2020).

35. AENOR Quantitative Analysis of Soluble Sulphate Content of a Soil; UNE 103201:1996. 1996. Available online: https://www.aenor.es (accessed on 20 October 2020).

36. UNI EN 12457-2 Characterisation of waste-Leaching-Compliance Test for Leaching of Granular Waste Materials and Sludges-Part 2: One Stage Batch Test at a Liquid to Solid Ratio of 10 1/kg for Materials with Particle Size Below $4 \mathrm{~mm}$ (without or with Size Reduction). 2004. Available online: https://www.aenor.es (accessed on 20 October 2020).

Publisher's Note: MDPI stays neutral with regard to jurisdictional claims in published maps and institutional affiliations.

(C) 2020 by the authors. Licensee MDPI, Basel, Switzerland. This article is an open access article distributed under the terms and conditions of the Creative Commons Attribution (CC BY) license (http://creativecommons.org/licenses/by/4.0/). 